\title{
Synthesis of an organic-inorganic hybrid material by solid state intercalation of 2-mercaptopyridine into $\mathrm{Na}$-, $\mathrm{Al}(\mathrm{III})$ - and Co(II)-montmorillonite
}

\author{
I BEKRI-ABBES* and E SRASRA \\ Unité de Recherche sur les Matériaux, Institut National de la Recherche Scientifique et Technique, BP 952050 \\ Hammam-Lif, Tunisia
}

MS received 2 September 2005; revised 8 March 2006

\begin{abstract}
The preparation of an organic-inorganic hybrid material by solid state intercalation of 2-mercaptopyridine (2Mpy) into Na-, Co(II)- and $\mathrm{Al}(\mathrm{III})$-montmorillonite has been studied using a variety of techniques. The extension of $d_{001}$ from XRD proves that the intercalation of 2-mercaptopyridine into Na-, Co(II)and $\mathrm{Al}$ (III)-mont occurs at ambient temperature in $5 \mathrm{mn}$. When the intercalated samples were heated at different temperatures, we found that the $d_{001}$ gave different values. For instance, for intercalated Al(III)- and $\mathrm{Co}(\mathrm{II})-, d_{001}$ remained unchanged for a temperature under $500^{\circ} \mathrm{C}$. However, for intercalated Na-mont, it shifted to $14 \AA$ for a temperature of $300^{\circ} \mathrm{C}$, the washing of different samples with a methanol solution shifted the $d_{001}$ of intercalated Na-mont to $14 \AA$. However, for intercalated $\mathrm{Al}$ (III) and Co(II), it did not change. This proves that in the case of Na-mont, the molecules of 2-mercaptopyridine interact with the clay through hydrogen bindings and physical interactions. However, for $\mathrm{Al}$ (III) and $\mathrm{Co}$ (II), it forms coordination linking and physical interaction. ${ }^{13} \mathrm{C}$ NMR and FTIR spectroscopy have been employed for the characterization of the intercalation compounds. Tautomeric equilibrium between thiol and thione species of 2-mercaptopyridine must be taken into account to explain the arrangement of molecular aggregates and their particular orientation in the interlayer space. The isotherm of adsorption-desorption of nitrogen and topographic AFM images prove that intercalation of $2 \mathrm{Mpy}$ is accompanied by a total blockage of clay porosity and an increase in roughness.
\end{abstract}

Keywords. Organic-inorganic hybrid materials; solid state intercalation; montmorillonite clay; 2-mercaptopyridine.

\section{Introduction}

The construction of organic-inorganic nano structure materials is an important target of modern materials research. The purpose behind such research is to develop functional materials. The smectite group, which includes montmorillonite, has enjoyed wide attention due to its interesting adsorptive/intercalation and cation-exchange properties.

Organoclay has received widespread attention in a number of industrial sectors including waste treatment (Koh and Dixon 2001; Koskinen and Hermison 2001; Beall 2003; Grosman et al 2004) catalysis, and electrodemodifiers. The synthesis, characterization and properties of smectite-organic intercalation compounds have been reported extensively (Theng 1997). The process often used for the preparation of organoclay is an intercalation into the clay in suspension state. These reactions are characterized by long time treatment and excessive use of orga-

\footnotetext{
*Author for correspondence (bekrimene@gmail.com)
}

nic solvent. Therefore, it is interesting to develop and test another efficient process of preparation of organoclay.

A process, which is not very frequently used and which allows the possibility of preparing compounds which are not accessible from solutions (Patil et al 1984), is the socalled solid-solid reaction. The latter is a mechanochemical adsorption that occurs between powders in the solid state (Rothenberg et al 2001). Solid-state intercalation of organic guest species into layered vanadium phosphorus oxide (Yamamoto et al 2001), zeolites (Lázár et al 1994) and layered clay minerals (Yariv and Lapides 2000; Khaorapapong et al 2001, 2002; Landau et al 2002) have been reported as a way of utilizing host structures. Solidstate intercalation can be split into two stages: one is the diffusion of guest species from the outer surfaces of guest solids and the other is the penetration of the guest species into the interlayer spaces.

Intercalation of pyridine and related derivatives in clays has been widely studied for several decades (Sabah and Celik 2002). Their intercalation can be achieved from the neutral molecules by interaction of the pyridine ring with the interlayer cations through water bridges and it can 
also be achieved by cation exchange from the corresponding protonated (pyridinium) derivatives. What is interesting is the fact that intercalated pyridines can adopt different orientations in the interlayer space depending on both the structure of such molecules and the nature of the interlayer cation.

We report here the intercalation of 2-mercaptopyridine (2Mpy, figure 1) into $\mathrm{Na}-\mathrm{Co}(\mathrm{II})$ - and $\mathrm{Al}(\mathrm{III})$-montmorillonite by solid-solid reaction. We have chosen this organic molecule for two principal reasons: (i) it is an interesting derivative of pyridine which contains functional groups (thiolate-S and aromatic-N) and therefore, it may interact with clay in different orientations and configurations, and (ii) it has the ability to both chelate and bridge transition metals.

We have characterized the intercalated products by $\mathrm{X}$ ray diffraction (XRD), atomic force microscopy (AFM), infrared spectroscopy (FTIR), azote adsorption-desorption and thermo XRD.

\section{Materials and methods}

Montmorillonite clay was obtained from the region of Zaghouan, from the East West of Tunisia. The presence of smectite was confirmed by the $d_{001}$ spacing of the sample after air drying, calcinations at $600^{\circ} \mathrm{C}$ for $2 \mathrm{~h}$ and glycol treatment. It was studied by El Hechi et al (2003) and Ayari et al (2004). In this study, we have shown that used smectite was essentially dioctahedral. By means of specific tests (test of lithium), it was found that it constitutes essentially of montmorillonite. Montmorillonites saturated with $\mathrm{Na}^{+}, \mathrm{Co}^{2+}$ and $\mathrm{Al}^{3+}$ were prepared by suspending $5 \mathrm{~g}$ of purified smectite in $200 \mathrm{ml}$ of freshly prepared $1 \mathrm{M}$ aqueous solution of the respective chloride salt $\left(\mathrm{Cl}_{3} \mathrm{Al}\right.$ and $\mathrm{Cl}_{2} \mathrm{Co}$ were purchased from Aldrich), and changing each solution after $24 \mathrm{~h}$. After 7 days of shaking, the clay was washed several times with distilled water until it was free of chloride (examined by $\mathrm{AgNO}_{3}$ solution). The amounts of $\mathrm{Na}, \mathrm{Al}$ and $\mathrm{Co}$ were determined after exchanging samples with the complex of ethylenediamine of copper (Bergaya 1997), and were respectively 101, 103 and $105 \mathrm{meq} / 100 \mathrm{~g}$ of Na-, Al- and Co-clay. 2Mercaptopyridine was purchased from Aldrich.

The resulting intercalation materials were characterized by chemical analysis (Perkin-Elmer $2400 \mathrm{CHN}$ analyser). The IR spectra were obtained with a Nicolet spectrophoto-

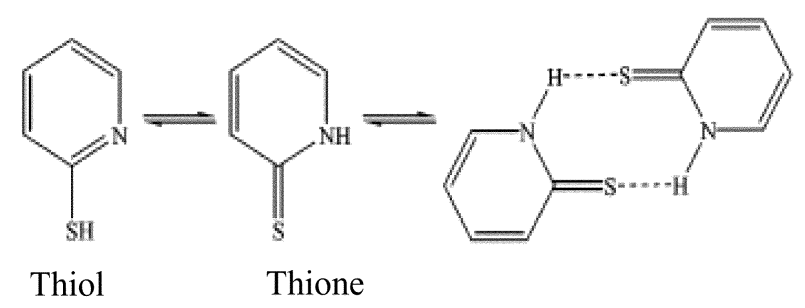

Figure 1. Chemical structure of 2-mercaptopyridine. meter (model 560) with a scanning range between 400 and $4000 \mathrm{~cm}^{-1}$. The samples were prepared as tablets diluted in $\mathrm{KBr}$ while we kept constant the sample/KBr ratio and the total weight of sample. The $75 \mathrm{MHz}{ }^{13} \mathrm{C}$ solid-state NMR experiments were carried out with a BRUKER spectrometer $(300 \mathrm{MHz})$.

The surface roughness was checked before and after the intercalation process by topological images obtained by AFM.

AFM images were recorded on a nanoscope II instrument in contact mode and in a region of $500 \times 500 \mathrm{~nm}^{2}$ with a scan rate of $1 \mathrm{~Hz}$ at $256 \times 256$ resolution, for sample preparation for AFM analysis. We used the method of Occelli et al (2000). Wafers were formed by pressing powders of samples at about $15,000 \mathrm{kPa}$ and were glued onto steel disks with epoxy resin and when the glue had dried, the atomic force microscope tip was carefully guided to the middle of the wafer thus beginning the analysis.

The RMS roughness was calculated from the following equation:

$$
\mathrm{RMS}=\sqrt{\frac{\sum_{i=1}^{N}\left(z_{\mathrm{i}}-z_{\mathrm{a}}\right)^{2}}{N-1} .}
$$

In this equation, $z_{\mathrm{i}}$ is the image height at pixel $i, z_{\mathrm{a}}$ the average height and $N$ the number of pixels in the AFM image. The interlayer space of organoclay was checked by XRD technique on a Panalytical diffractometer using $\mathrm{Cu}$ radiation. Nitrogen sorption isotherms were obtained with a Quantachrome instrument (Autosorb), prior to the analysis, the samples were outgassed in vacuum at $100^{\circ} \mathrm{C}$ for $2 \mathrm{~h}$. BET surface areas were calculated from isotherm at relative pressures ranging from 0.05-0.30 (Brunauer et al 1938).

The t-method of Halsey (1948) was used for the determination of micropore volume in the presence of mesopores. This technique involves the measurement of nitrogen adsorbed by the sample at various low pressure values.

The intercalation of $2 \mathrm{Mpy}$ into Al-, Co- and Na-montmorillonite was achieved via solid-solid reactions. The mixtures of the hosts and the guest species were ground manually using an agate mortar and pestle at room temperature for $5 \mathrm{~min}$. The molar ratio of $2 \mathrm{Mpy}$ to the interlayer $\mathrm{Na}, \mathrm{Co}, \mathrm{Al}$ cation was 3:1. When the solid-solid reactions were achieved, the intercalation compounds were washed repeatedly with $n$-heptane in order to remove excess of $2 \mathrm{Mpy}$.

\section{Results and discussion}

\subsection{Spectroscopic studies}

Due to its structure (heterogeneous cyclic structure and the presence of mobile hydrogen), 2-mercaptopyridine molecules coexist in two tautomeric forms, thione and thiol (figure 1). 
The predominance of a tautomeric form up to the other depends on many factors such as state of molecule (gaseous, solid), polarity of solvent and even temperature and $\mathrm{pH}$ solution.

It is well known that in solid state $2 \mathrm{Mpy}$ predominates in its thione tautomer conformation, forming molecular aggregates that are organized as dimmers through hydrogen bonding interactions (Zhang et al 2003) (figure 1). In order to determine the tautomeric form adopted by $2 \mathrm{Mpy}$ molecules after reaction with clay, IR and ${ }^{13} \mathrm{C}$ spectroscopy have been used.

Figure 2 shows the IR spectra of the starting mercaptopyridine, pure clay and Na-, Co-, Al-montmorillonite treated with $2 \mathrm{Mpy}$. Their assignment of vibrational modes is represented in table 1 .

The bands of $2 \mathrm{Mpy}$ have been assigned by means of theoretical calculation considering their thiol-thione tautomeric forms (Zhang et al 2003). The characteristic IR bands observed in the spectrum of pure $2 \mathrm{Mpy}$ (figure b) agree well with the theoretical bands predicted for $2 \mathrm{Mpy}$ in their thione form. However, after intercalation into $\mathrm{Co}$ and Al-montmorillonite, the characteristic bands of the thione form $\left(1628,1371,732 \mathrm{~cm}^{-1}\right.$ for Co-mont and $1628,1370,730 \mathrm{~cm}^{-1}$ for Al-mont) are observed in addition to the thiol bands (1452, 1421 and $761 \mathrm{~cm}^{-1}$ for intercalated Al-mont compound and 1448, 1421 and $757 \mathrm{~cm}^{-1}$ for Co-intercalated compound). Moreover, the band at $1582 \mathrm{~cm}^{-1}$ that is predicted in the thiol form, corresponding to stretching vibrations of the pyridine ring and to - SH bending, appears in Al-mont and Co-mont as a strong band at $1579 \mathrm{~cm}^{-1}$ for intercalated Co-mont and at $1575 \mathrm{~cm}^{-1}$ for intercalated Al-mont. For intercalated Na-mont, we observe only the characteristic bands of the thiol form. It is interesting to note that in the case of Coand Al-mont, $v \mathrm{OH}$ bands of water molecules (at $3438 \mathrm{~cm}^{-1}$ ) and $\delta \mathrm{OH}$ (at $1640 \mathrm{~cm}^{-1}$ ) initially present in the interlayer space of the clay disappeared in the spectrum (figures $2 \mathrm{~d}$, e) indicating that the intercalation of $2 \mathrm{Mpy}$ thiol-thione replaces these water molecules. However, in the case of Na-mont these bands increase in area which indicates that intercalated Na-mont adsorbs water. From these results, we can assume that $2 \mathrm{Mpy}$ interacts with Al-, Co-mont in a different way from that of intercalated Na-mont. In the case of Co- and Al-mont, it is obvious that $2 \mathrm{Mpy}$ molecules take the place of water and interact directly with $\mathrm{Co}^{2+}$ and $\mathrm{Al}^{3+}$ cations. From FTIR study, we cannot deduce that $2 \mathrm{Mpy}$ forms coordination linking with $\mathrm{Co}^{2+}$ and $\mathrm{Al}^{3+}$ because metal-sulfur bonds are located at wavelengths below the Nicolet 560 FT-IR series spectrometer's detection limit of $400 \mathrm{~cm}^{-1}$. For intercalated Namont, we observe an increase of the intensity of water bands, probably the mode of interaction in this case is not the same, $\mathrm{H}_{2} \mathrm{O}$ coexists with $2 \mathrm{Mpy}$ molecules and forms hydrogen linking with $\mathrm{S}-\mathrm{H}$ of the thiol form. The increased water adsorption is due to grinding of mixture which is carried out in atmospheric ambient and in an open system.
Due to the complexity of ${ }^{13} \mathrm{C}$ NMR spectra when tautomeric species coexist, it has been necessary to use theoretical models based on spectroscopic simulation tools (Montserrat et al 2005).

The ${ }^{13} \mathrm{C}$ NMR spectrum of pure $2 \mathrm{Mpy}$ (figure a) shows well defined signals at 180,149, 133 and 118 ppm, assignable to $\mathrm{C} 2 *, \mathrm{C} 6 *, \mathrm{C} 3 *$ and $\mathrm{C}^{*} *$ carbon of the thione tautomer. The ${ }^{13} \mathrm{C}$ NMR spectrum of the intercalated Namontmorillonite presents the signals of the thiol tautomeric form $(153,122 \mathrm{ppm})$ (figure $3 \mathrm{c}$ ). These signals can be assigned to $\mathrm{C} 2, \mathrm{C} 5$ and $\mathrm{C} 6$.

For Al-mont and Co-mont intercalated samples, we observe signals which can be assigned to thiol and thione form, evidencing in this case the coexistence of both tautomeric species (thiol and thione). These results are in agreement with the IR spectroscopic results.

\subsection{Thermal analysis (thermo-XRD)}

The XRD patterns along with basal spacing $\left(d_{001}\right)$ data of the intercalated 2 Mpy-mont composites are shown in figure 4. It reveals that $d_{001}$ is about $19 \cdot 1 \AA$ for $\mathrm{Na}$ intercalated sample, taking into account the thickness of the silicate layer (about 9.6 $\AA$ ), and the thickness of mercaptopyridine molecules, a $\Delta d_{\mathrm{L}}$ value of $3.2 \AA$ (Montserrat et al 2005). The increase of the interlayer distance for this compound is calculated from the corresponding $d_{001}$ space. We have found that this value corresponds to the thickness of three layers of 2Mpy molecules disposed with the ring parallel to the plane defined by the silicate layers, for intercalated Co-mont and Al-mont, the basal spacing is about $\sim 15 \AA$ for the two compounds, which supposes that in these cases 2Mpy molecules take the same configuration which is different from that of intercalated Na-mont compound.

It is interesting to note that the washing of intercalated Na-mont with methanol decreases the $d_{001}$ to $13 \AA$, however, for Co- and Al-mont, it did not change the $d_{001}$, which proves that in the case of Co- and Al-mont, 2Mpy molecules form with Al- and Co-mont a configuration more stable than that of Na-mont, probably they form coordination bonds.

In order to evaluate the mode of interaction with the intercalated sample, we have heated different compounds in temperatures ranging from $300-650^{\circ} \mathrm{C}$. The heating of different intercalated compounds proves this suggestion.

The $d_{001}$ of unheated Na-mont intercalated compound is about $19 \AA$, this trilayer intercalated compound is not stable by heating at a temperature of $300^{\circ} \mathrm{C}$ for $2 \mathrm{~h}, d_{001}$ decreases to $14 \cdot 2 \AA$, which corresponds to a monolayer arrangement, therefore, the first two layers are less stable than the third one. This value is unstable under a temperature of $400^{\circ} \mathrm{C}$, it shifts to about $12 \AA$, the IR spectra of intercalated Na-mont (not shown) heated at $300^{\circ} \mathrm{C}$ shows 

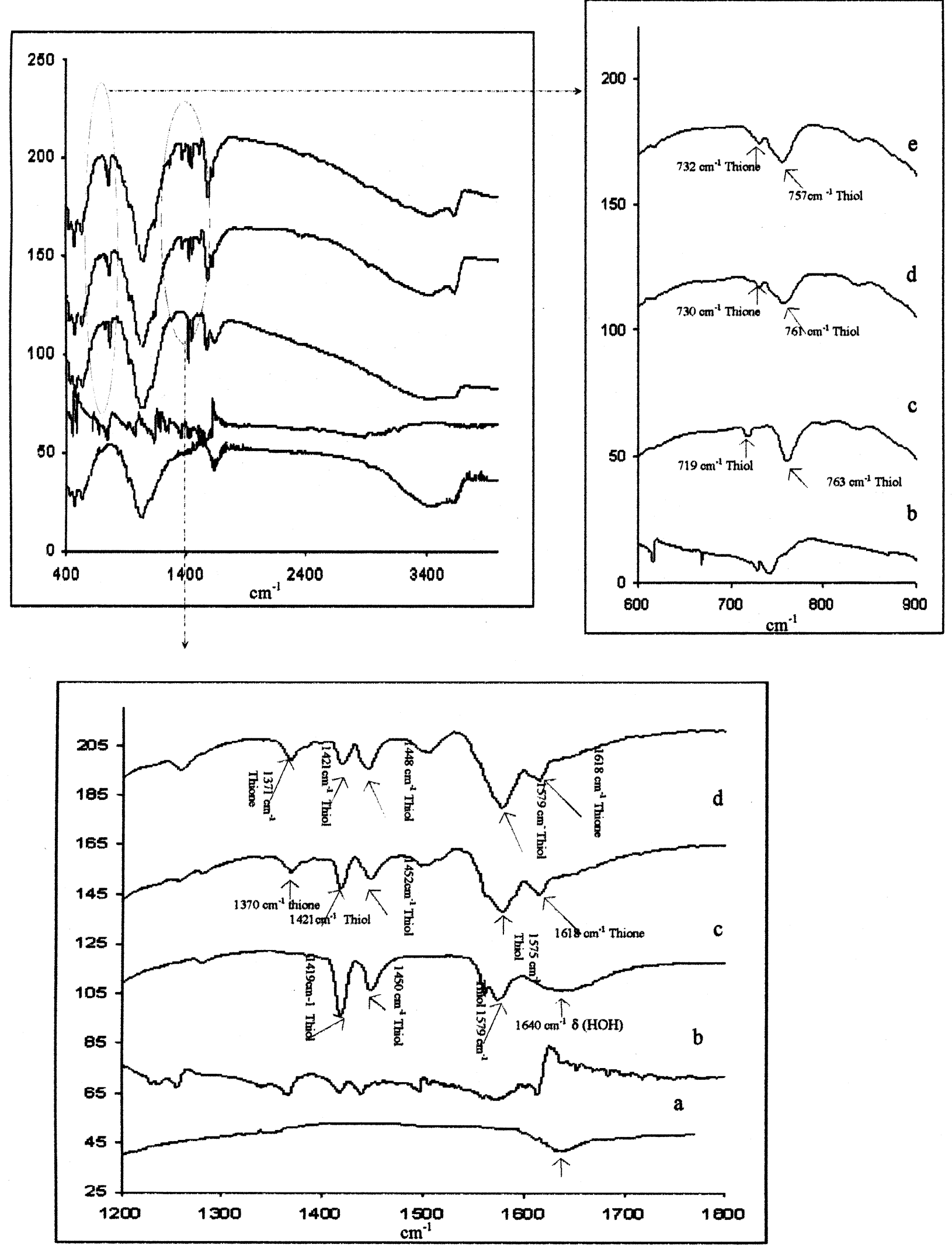

Figure 2. IR spectra (4000-400 $\mathrm{cm}^{-1}$ region) of (a) pure clay, (b) pure $2 \mathrm{Mpy}$, (c) $2 \mathrm{Mpy}$ intercalated in Na-montmorillonite, (d) $2 \mathrm{Mpy}$ intercalated in Al-montmorillonite, (e) $2 \mathrm{Mpy}$ intercalated in Co-montmorillonite; the right spectrum represents a magnification in the $600-900 \mathrm{~cm}^{-1}$ region and the down spectrum represents a magnification in $1200-1600 \mathrm{~cm}^{-1}$ region. 
Table 1. Frequencies $\left(\mathrm{cm}^{-1}\right)$ and assignment of vibrational modes in IR spectrum of $2 \mathrm{Mpy}$ molecule in its thiol-thione tautomeric forms ${ }^{\dagger}$ and corresponding frequency of composites.

\begin{tabular}{|c|c|c|c|c|c|c|c|}
\hline $\begin{array}{l}\text { 2Mpy } \\
\text { pure solid }\end{array}$ & $\begin{array}{c}\text { 2Mpy } \\
\text { Na-mont }\end{array}$ & $\begin{array}{c}\text { 2Mpy } \\
\text { Al-mont }\end{array}$ & $\begin{array}{c}2 \mathrm{Mpy} \\
\text { Co-mont }\end{array}$ & $\begin{array}{l}\text { 2Mpy-thione* } \\
\text { (calcd) }\end{array}$ & Assignment & $\begin{array}{l}\text { 2Mpy-thiol* } \\
\text { (calcd) }\end{array}$ & Assignment \\
\hline \multirow[t]{2}{*}{1614} & \multirow{3}{*}{$\begin{array}{c}- \\
1579\end{array}$} & 1628 & 1628 & \multirow[t]{2}{*}{1641} & \multirow[t]{2}{*}{$v_{8 b}$} & 1601 & \multirow{3}{*}{$\mathrm{v}_{8 \mathrm{~b}}, \delta_{\mathrm{Bb}}$} \\
\hline & & 1575 & 1579 & & & 1582 & \\
\hline 1576 & & 1569 & 1569 & 1569 & $v_{8 \mathrm{a}}, \delta_{\mathrm{CNH}}$ & & \\
\hline \multirow{2}{*}{1441} & 1450 & 1452 & 1448 & \multirow{2}{*}{1467} & \multirow{2}{*}{$v_{19 a}, \delta_{\mathrm{CNH}}$} & 1461 & $v_{14}$ \\
\hline & 1419 & 1421 & 1421 & & & 1416 & $v_{19 b}$ \\
\hline 1369 & - & 1370 & 1371 & 1345 & $v_{3}$ & \multirow{3}{*}{764} & \multirow{3}{*}{$\delta_{10 \mathrm{~b}}$} \\
\hline \multirow[t]{2}{*}{743} & 763 & 761 & 757 & & & & \\
\hline & - & 730 & 732 & 733 & $v_{11}, \delta_{\mathrm{CNH}(\text { out of plane) }}$ & & \\
\hline
\end{tabular}

*The assignment of the vibrational modes is taken from the normal mode assignment of benzene (Zhang et al 2003); ${ }^{\dagger}$ all the frequencies are expressed in wave numbers.

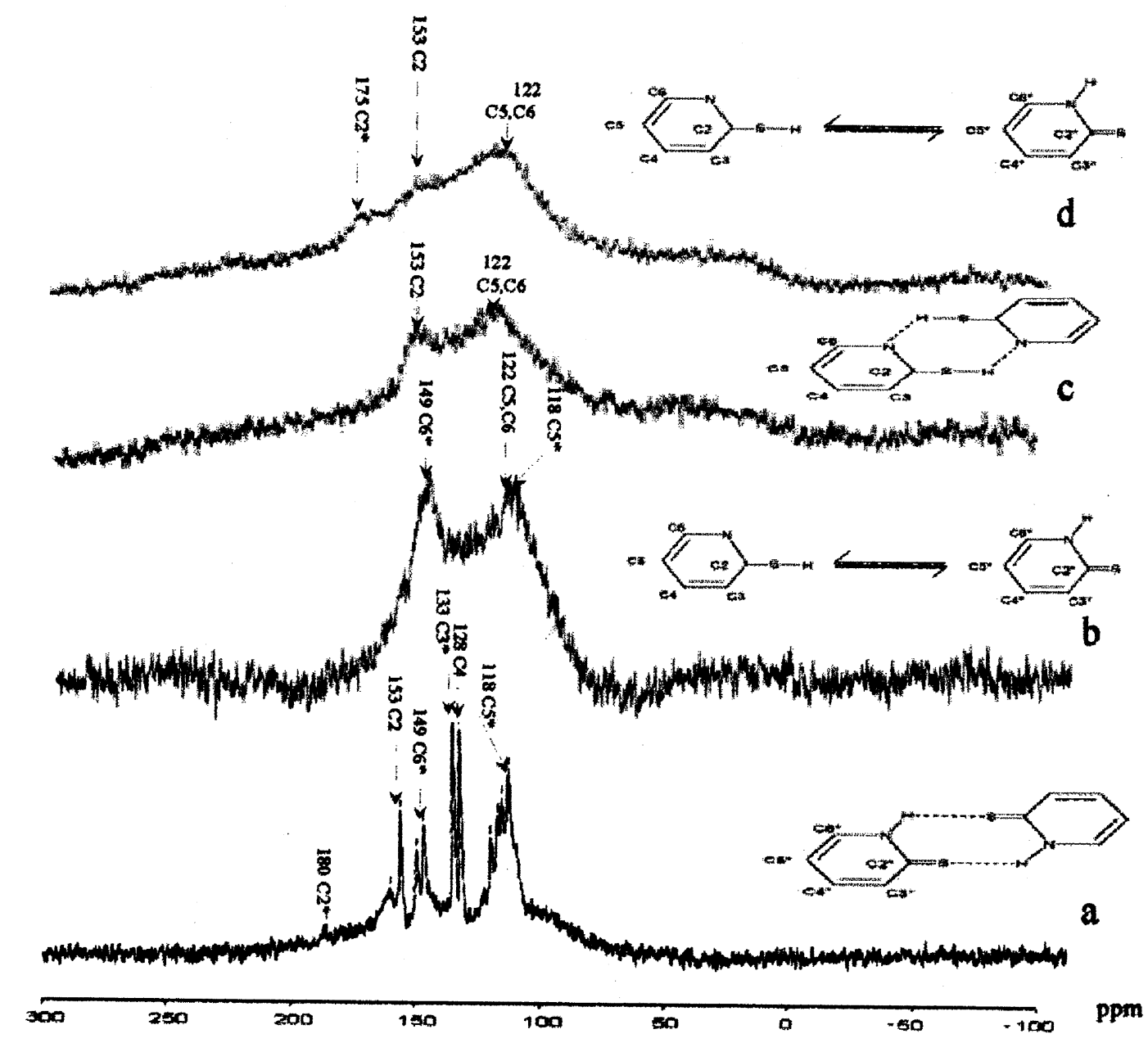

Figure 3. ${ }^{13} \mathrm{C}$ NMR spectra of (a) pure $2 \mathrm{Mpy}$, (b) Al-montmorillonite treated with $2 \mathrm{Mpy}$, (c) Namontmorillonite treated with $2 \mathrm{Mpy}$ and (d) Co-montmorillonite treated with $2 \mathrm{Mpy}$.

the coexistence of some peaks of $2 \mathrm{MPy}$, for the sample heated at $400^{\circ} \mathrm{C}$, it did not show any peaks of $2 \mathrm{Mpy}$. Up to $550, d_{001}$ decreases to $10 \AA$ confirming completely collapsed structure of montmorillonite. However, in the case of intercalated Al- and Co-montmorillonite compound, the $d_{001}$ are stable under a temperature of $500^{\circ} \mathrm{C}$; upon further heating up to $650^{\circ} \mathrm{C}$, the $d_{001}$ reflection shows a value of $10 \AA$, confirming a completely collapsed structure of montmorillonite. These results prove that in the case of intercalated $\mathrm{Al}$ - and Co-mont, molecules of $2 \mathrm{Mpy}$ form 
Table 2. Chemical compositions of the products.

\begin{tabular}{lccccc}
\hline Intercalated compound & $\mathrm{C}($ molar \%) & $\mathrm{N}$ (molar \%) & $\mathrm{H}($ molar \%) & $\mathrm{C}: \mathrm{H}$ & $\mathrm{C}: \mathrm{N}$ \\
\hline Intercalated Na-mont & 1.5 & 0.278 & 1.4 & 4.86 & 1 \\
Intercalated Co-mont & 0.76 & 0.14 & 0.75 & 4.95 & 1 \\
Intercalated Al-mont & 0.5 & 0.1 & 1.6 & 4.85 & 1 \\
\hline
\end{tabular}

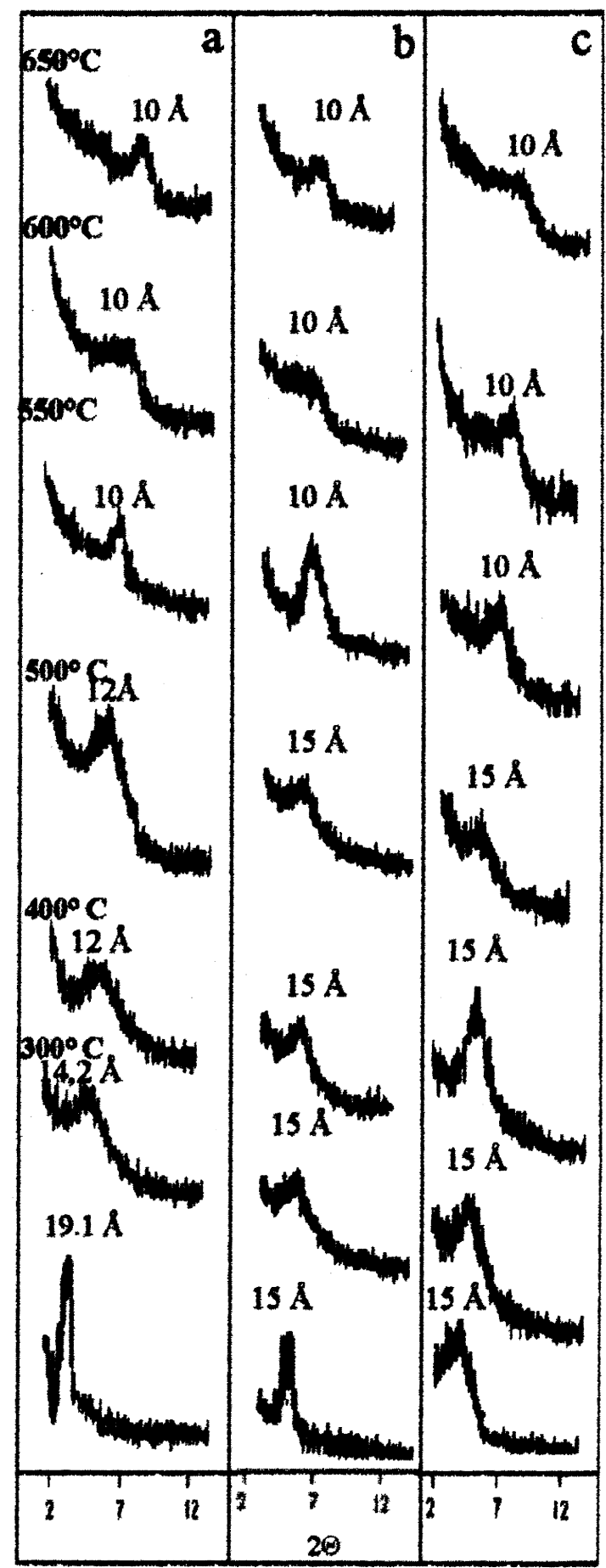

Figure 4. X-ray diffraction patterns and basal spacing $\left(d_{001}\right)$ of intercalated composites heated at different temperatures for $2 \mathrm{~h}$ in air atmosphere. coordinating links with $\mathrm{Al}$ and Co cations, however, for intercalated Na-mont, the $\mathrm{S}-\mathrm{H}$ of the thiol interacts with $\mathrm{H}_{2} \mathrm{O}$ by hydrogen interactions.

\subsection{CHN analysis}

In table 2, we represent the CHN molar composition of different intercalated compounds. From these values, we can deduce that the $\mathrm{C}: \mathrm{N}: \mathrm{H}$ ratio of the product is in good agreement with that of the $2 \mathrm{Mpy}$ molecule which proves the non-degradation of $2 \mathrm{Mpy}$. The ratio of adsorbed 2Mpy to interlayer $\mathrm{Na}, \mathrm{Co}, \mathrm{Al}$ cations was estimated to be $\sim 3: 1$, based on $\mathrm{C}$ content.

\subsection{Textural study}

Figure 5 represents the nitrogen adsorption-desorption isotherm of the samples, following the classification of BDDT (Deming et al 2004), all the adsorption isotherms are of type II, this type of isotherm represents unrestricted monolayer-multilayer adsorption, point B which represents the start of the linear central section of the isotherm, is usually taken to indicate the relative pressure at which monolayer coverage is complete.

For different samples, this value is about $0.4 P_{0}$ (in our analysis $P_{0}$ is equal to ambient pressure). The Boer (De Boer 1958) hysteresis classification indicates that the hysteresis is of type B. We have selected Vt-method for microspores determination, the microspores of these samples are given in table 3 , specific surface area is very low in all the intercalated solids, being between 4 and $15 \mathrm{~m}^{2} / \mathrm{g}$ in most of them. This clearly indicates a total blockage of clay porosity by the intercalation of the organic molecules.

AFM images have been used by many researchers to characterize the morphology and roughness of materials such as polymeric membrane (Bowen and Donev 2000; Jones et al 2001; Ochoa et al 2001), inorganic materials such as alumina (Xu et al 2002), and clay minerals.

It was essentially limited for size characterization of clay particles (Plaschke et al 2001, 2002; Tounrassat et al 2003; Martinez et al 2004), but study of the morphology of organoclay by AFM images is not reported. AFM images were recorded for different samples and presented in figure 6. The RMS roughness was evaluated for each of the samples using (1). These results are represented in figure 6 and it ranged from 9.9-15 nm for Na-, $\mathrm{Al}(\mathrm{III})$ - and $\mathrm{Co}(\mathrm{II})$ montmorillonite. After intercalation, these values increased 

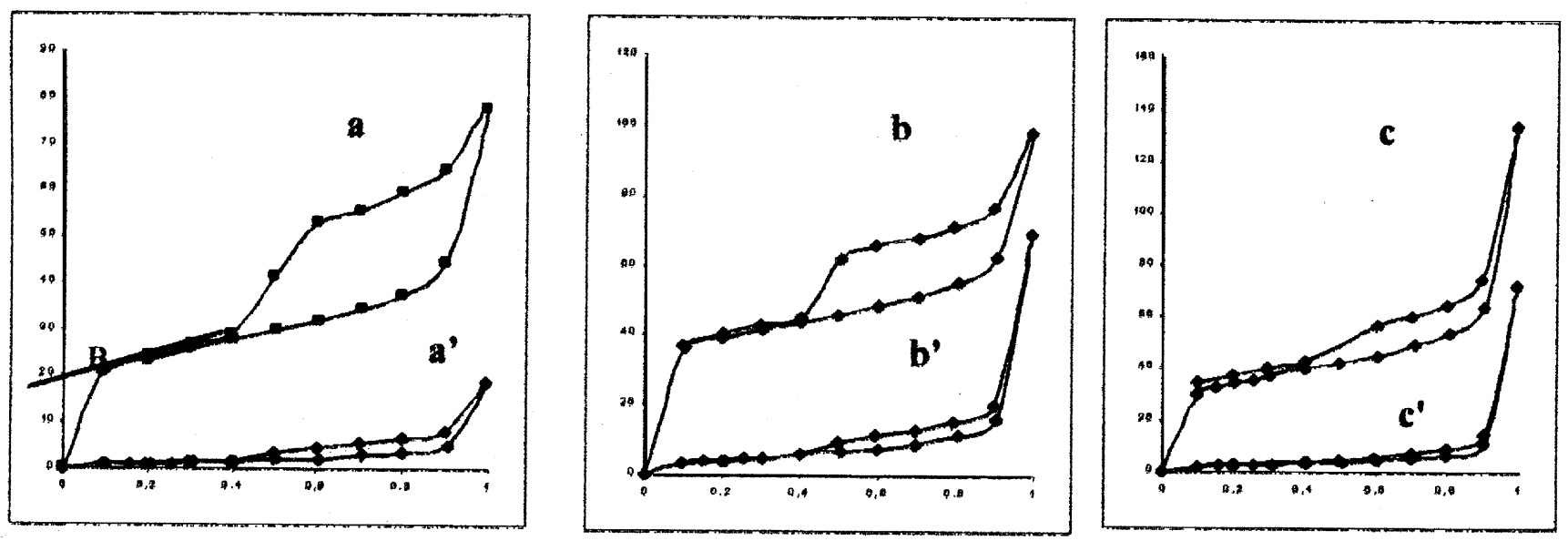

Figure 5. Adsorption and desorption isotherm for (a) Na-mont, (a') 2Mpy-Na-mont, (b) Al-mont, (b') 2Mpy-Al-mont, (c) Comont and (c') 2Mpy-Co-mont.
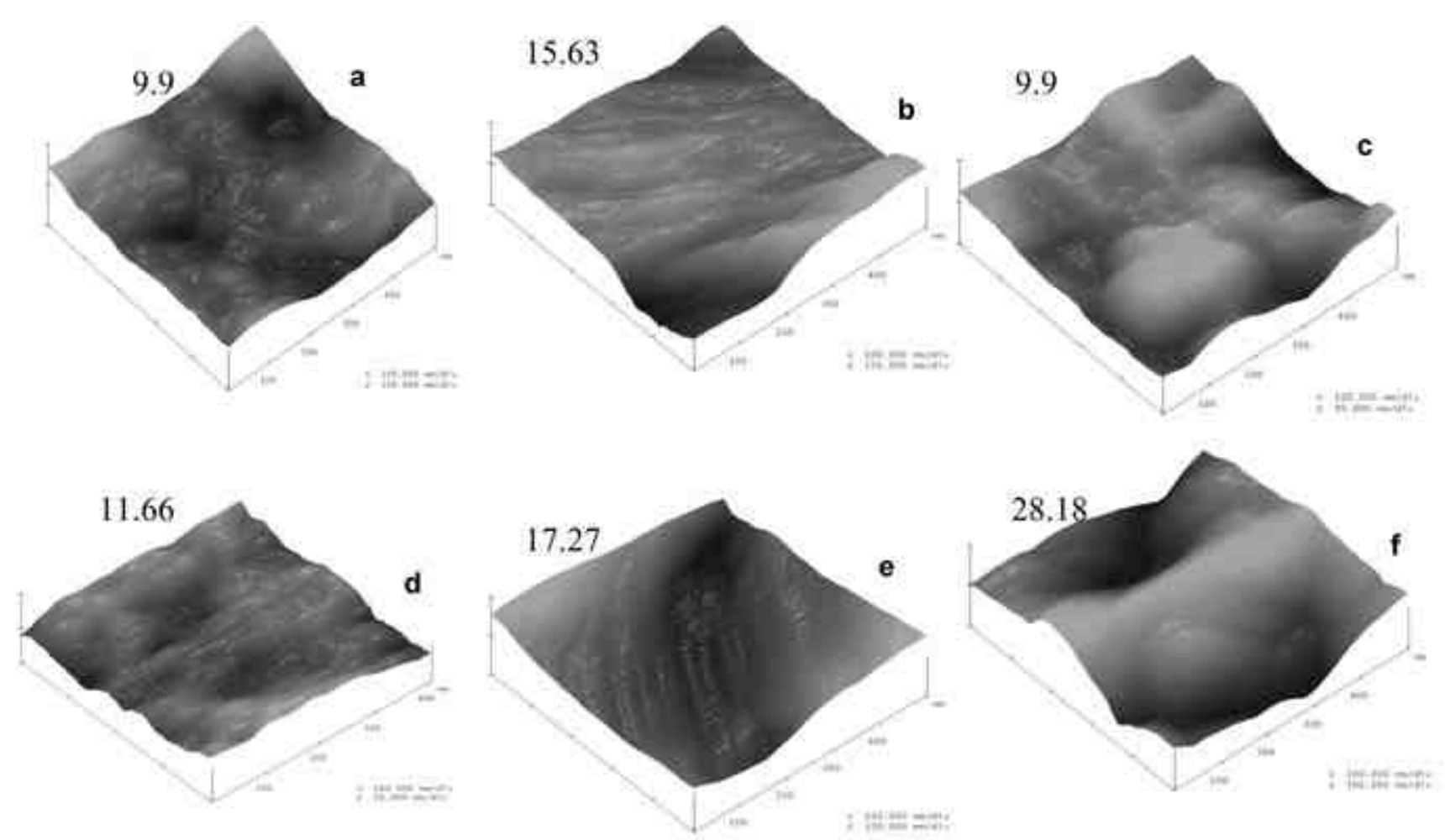

Figure 6. AFM images of (a) Na-mont, (b) Al-mont, (c) Co-mont, (d) intercalated Na-mont, (e) intercalated Al-mont and (f) intercalated Co-mont.

Table 3. Microspore volume and specific surface.

\begin{tabular}{lcc}
\hline & $\begin{array}{c}\text { Specific surface } \\
\left(\mathrm{m}^{2} / \mathrm{g}\right)\end{array}$ & $\begin{array}{c}\text { t-Method microspore } \\
\text { volume }\left(10^{-2} \mathrm{cc} / \mathrm{g}\right)\end{array}$ \\
\hline Na-mont & $77 \cdot 38$ & $2 \cdot 083$ \\
Intercalated Na-mont & $4 \cdot 26$ & 0 \\
Co-mont & $111 \cdot 11$ & $1 \cdot 89$ \\
Intercalated Co-mont & $9 \cdot 38$ & 0 \\
Al-mont & $122 \cdot 5$ & $3 \cdot 19$ \\
Intercalated Al-mont & $15 \cdot 7$ & 0 \\
\hline
\end{tabular}

considerably, due to intercalation of bulky compound into the interlayer space of montmorillonite.

\subsection{Molecular arrangement and structure models}

Several authors have studied the coordination chemistry of pyridine thiol-thione (Umakoshi et al 1990; Javier Cabeza et al 1998; Alonso and Salomo 1999; Jung et al 1999; Matthew et al 2001; Rafat et al 2004). 2-Mercapto- 
pyridine can act both as thione and as thiolate ligand to adopt to a variety of coordination modes (figure 7). In our

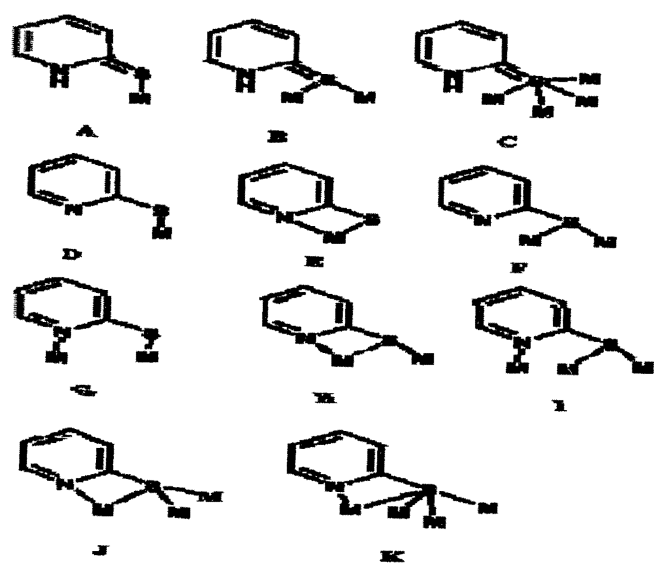

Figure 7. Coordination modes of pyridine thiol-thione with different $\mathrm{M}$ metal cations.

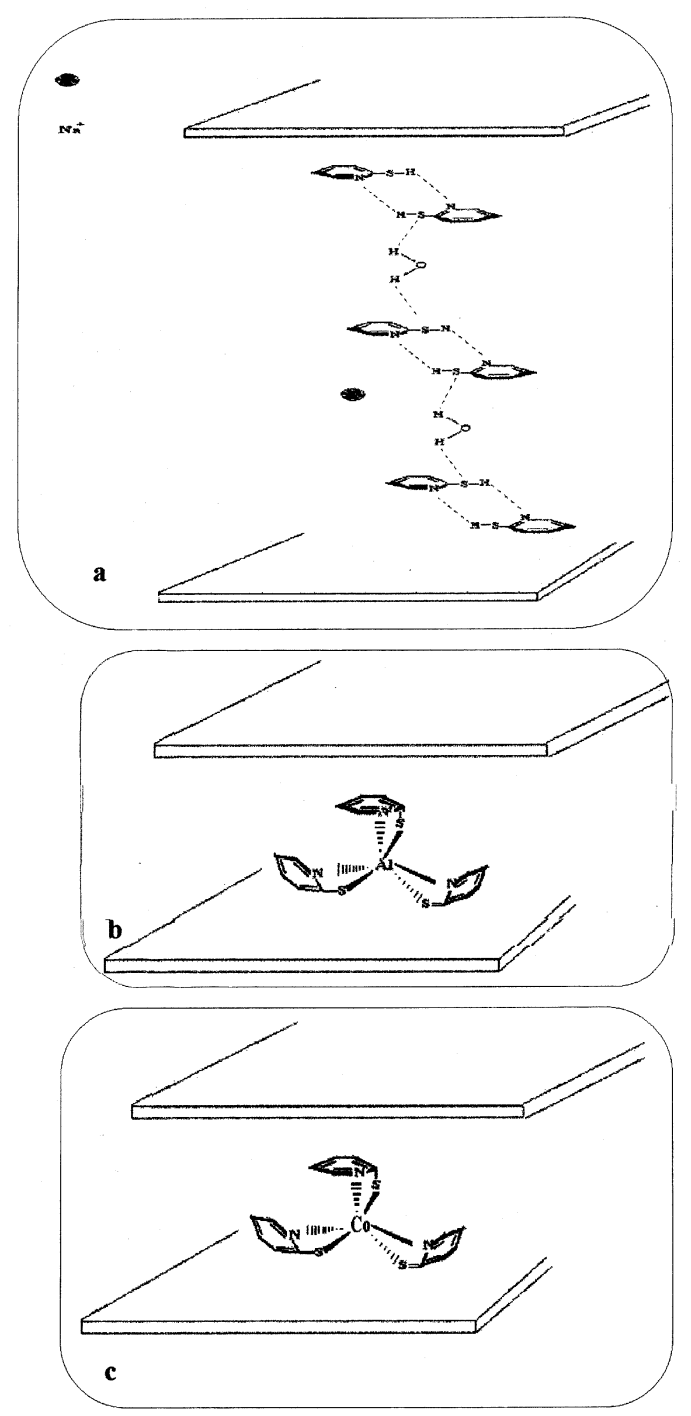

Figure 8. Schematic summary of proposed molecular models in the interaction of $2 \mathrm{Mpy}$ with a. Na-montmorillonite, b. $\mathrm{Al}(\mathrm{II})$-montmorillonite and c. Co-montmorillonite. case, we have studied Co(II). The complexes of $\mathrm{Co}(\mathrm{III})$ with 2-mercaptopyridine have been reported to form an octahedral structure with two thione molecules and only one thiol (Jung et al 1999). It is well known that two $\mathrm{Co}(\mathrm{III})$ and $\mathrm{Co}(\mathrm{II})$ form octahedral complex structure. From FTIR study, we have found that for $\mathrm{Al}$ and $\mathrm{Co}$ intercalated compounds the peaks of the thiol form predominates over the thione peaks, therefore, we can suppose that there are two thiol molecules and only one thione molecule around the $\mathrm{Al}(\mathrm{III})$ and $\mathrm{Co}(\mathrm{II})$ cations. From these results, we can postulate various molecular models to explain the interaction of $2 \mathrm{Mpy}$ with $\mathrm{Na}-\mathrm{Al}(\mathrm{III})-$ and $\mathrm{Co}(\mathrm{II})$-mont and this is shown in figure 8 .

\section{Conclusions}

2-Mercaptopyridine molecules were successfully intercalated into the interlayer spaces of sodium, cobalt(II)-, aluminium(III)-montmorillonites by solid-solid reactions. The intercalated molecules of 2Mpy are thought to form coordinating compound in the interlayer spaces of Aland Co-montmorillonites. However, they are linked through hydrogen bindings in the case of Na-mont.

The tautomeric predominance species present in the intercalation medium depends on the nature of cation, for aluminium(III) and cobalt(II), the two tautomeric forms coexist with slight predominance of the thiol tautomeric form, however, for sodium, only the thiol form coexists. In all cases, an almost total blockage of the interlayer porosity of the clays is done by the organic molecules and the intercalation is accompanied by an increase of the surface roughness.

\section{References}

Alonso C and Salomo A B 1999 Langmuir 57014

Ayari F, Srasra E and Trabelsi-Ayadi M 2004 J. Phys. IV 122 229

Beall G W 2003 Appl. Clay Sci. 2411

Bergaya F 1997 Appl. Clay Sci. 12275

Bowen W R and Donev T A 2000 J. Colloid Interface Sci. 229 544

Brunauer S, Emmett P and Teller E 1938 J. Am. Chem. Soc. 60 309

De Boer J H 1958 The structure and properties of porous materials (London: Butterworths) p. 68

Deming L S, Deming W S and Teller E 1940 J. Am. Chem. Soc. 621723

El Hechi A, Srasra E, Amari A and Tlig S 2003 Africa Geosci. Rev. 10215

Grosman L, Raw-Acha C, Gerst Z and Mingelgrin U 2004 Appl. Clay Sci. 24159

Halsey G D 1948 J. Chem. Phys. 16931

Javier Cabeza A, Lamazares A, Riera V and Trivedi R 1998 Organometallics 175580

Jones C D, Fidalgo M, Wiesner M R and Barron A R $2001 \mathrm{~J}$. Membrane Sci. 193175 
Jung O S, Kim Y T, Kim Y J, Chon J K and Chae H K 1999 Bull. Korean Chem. Soc. 20648

Khaorapapong N, Kuroda K, Hashizume H and Ogawa M 2001 Appl. Clay Sci. 1969

Khaorapapong N, Kuroda K and Ogawa M 2002 Clays Clay Miner. 50428

Koh S and Dixon J B 2001 Appl. Clay Sci. 18111

Koskinen W C and Hermosin M C 2001 Appl. Clay Sci. 18 223

Landau A, Zaban A, Lapides I and Yariv S 2002 J. Thermal Anal. 70103

Lázár K, Pál-Borbèly G, Beyer H K and Karge H G 1994 J. Chem. Soc. Faraday Trans. 901329

Martinez V, Arbeloa F L, Prieto J B, Loepez T A and Larbeloa I 2004 Langmuir 205709

Montserrat C, Darder M, Aranda P and Ruiz-Hitzky E 2005 Chem. Mater. 17708

Occelli M L, Bertrand J A, Gould S A C and Dominguez J M 2000 Microporous Mesoporous Mater. 34195

Ochoa N A, Pádanos P, Palacio L, Pagliero C, Marchese J and Hernández A 2001 J. Membrane Sci. 187227

Patil O, Curtin D Y and Paul I C 1984 J. Am. Chem. Soc. 106 348
Plaschke M, Schäfer T, Bundschuh T, Ngo Manh T N, Knopp R, Geckeis H and Kim J I 2001 Anal. Chem. 734338

Plaschke M, Mer J R and Kim J I 2002 Environ. Sci. Technol. 364483

Rafat F, Siddiqi M Y and Siddiqi K S 2004 J. Serb. Chem. Soc. 69641

Rothenberg G, Downie A P, Raston C L and Scott J L $2001 \mathrm{~J}$. Am. Chem. Soc. 1238701

Sabah E and Celik M S 2002 J. Colloid Interface Sci. 25133

Theng B K G 1997 The chemistry of clay-organic reactions (London: Adam Hilger)

Tounrassat C, Neaman A, Villieras F, Bosbach D and Charlet L 2003 Am. Miner. 881989

Umakoshi K, Ichimura A, Kinoshita I and Ooi S 1990 Inorg. Chem. 294005

Xu C, Xue Q, Zhong Y, Cui Y, Ba L, Zhao B and Gu N 2002 Nanotechnology 1347

Yariv S and Lapides I 2000 J. Mater. Synthesis Processing 8 223

Yamamoto N, Okuhara T and Nakato T 2001 J. Mater. Chem. 111858

Zhang H L, Evans S D, Henderson J R and Miles T H $2003 \mathrm{~J}$. Phys. Chem. B107 6087 